\title{
DIGITAL TRANSFORMATION STRATEGIES: CONVERSATIONAL COMMERCE
}

\author{
Gonçalo Cordeiro de Sousa, goncalocs@gmail.com \\ ISCTE-IUL \\ Renato Jorge Lopes da Costa, renato_jorge_costa@iscte-iul.pt \\ ISCTE-IUL \\ Leandro Pereira, leandro.pereira@iscte-iul.pt \\ ISCTE-IUL \\ Carlos Jeronimo, Carlos.Miguel.Jeronimo@iscte-iul.pt \\ ISCTE-IUL
}

\begin{abstract}
With the evolution of technology and the consequent proliferation of the use of the internet for online shopping, and allied to the strong globalization of global commerce, which has online commerce as the highest exponent, it is increasingly difficult for companies to gain a competitive advantage over its competitors, making it fundamental to place consumer satisfaction at the heart of its business. This research intends to analyze how the use of natural language interfaces, together with a system of intelligent recommendation, that is to say, the concept developed by Chris Messina (2015), Conversational Commerce, could be a differentiating factor in the relationship of companies with its consumers, allowing not only to gain a competitive advantage, but to influence company reputation improving the brand image. This research and its results demonstrate that the use of these conversational interfaces, supported by natural language, increases trust and consumer satisfaction, making the purchasing process more fluid, flexible, convenient and fast, thus gaining a market advantage over its competitors.
\end{abstract}

KEYWORDS: E-commerce, Chatbots, Conversational Commerce, Natural language dialogue. 